\title{
A PESQUISA PSICANALÍTICA DE FENÔMENOS SOCIAIS: ALGUMAS CONSIDERAÇÕES
}

PSYCHOANALYTICAL RESEARCH ON SOCIAL PHENOMENA: A FEW CONSIDERATIONS

LA INVESTIGACIÓN PSICOANALÍTICA DE FENÓMENOS SOCIALES: ALGUNAS CONSIDERACIONES

\author{
Maria Cione Chrisóstomo* \\ Jacqueline de Oliveira Moreira ${ }^{* *}$ \\ Andréa Maria Campos Guerra** \\ Fuad Kyrillos Neto ${ }^{* * * *}$
}

\begin{abstract}
RESUMO
Este artigo parte de uma breve reflexão sobre a relação da psicanálise com a ciência, para, posteriormente, pensar as possibilidades de intervenção da primeira nas pesquisas que ultrapassam a clínica. Constata-se que a psicanálise, como a ciência, apresenta-se de dupla forma: se, por um lado, é herdeira da ciência moderna, por outro, propõe a subversão do sujeito pela lógica do inconsciente. O objeto da investigação psicanalítica é o sujeito que fala. Assim, deve-se buscar a precisão no terreno da linguagem e ordenar os fenômenos a partir da hipótese de que o inconsciente está estruturado como linguagem. Assevera-se que as perspectivas para pensar a pesquisa psicanalítica são tributárias da fidelidade aos significantes deixando-se surpreender por sua captura e por seus escapes. Conclui-se, ressaltando que a ênfase na apreensão singular do real, presentificada no fato social, é o pilar da orientação metodológica da psicanálise aplicada à pesquisa de fenômenos sociais.
\end{abstract}

Palavras-chave: Pesquisa. Psicanálise. Sociedade. Sujeito. Linguagem.

\begin{abstract}
This article proposes a brief reflection on the relation between psychoanalysis and science, in order to consider the possibilities of intervention of the former in researches that surpass clinic. We observed that psychoanalysis,
\end{abstract}

\footnotetext{
Texto recebido em 21 de janeiro de 2015 e aprovado para publicação em 13 de agosto de 2016.

"Mestra em Psicologia pela Pontifícia Universidade Católica de Minas Gerais (PUC Minas). Endereço: Avenida Itaú, 525 - Dom Cabral, Belo Horizonte-MG, Brasil. CEP: 30535-012. Telefone: (31) 3319-4568. E-mail: mcchrisos@yahoo.com.br.

**Docente do Programa de Pós Graduação em Psicologia da PUC Minas. Endereço: Avenida Itaú, 525 - Dom Cabral, Belo Horizonte-MG, Brasil. CEP: 30535-012. Telefone: (31) 3319-4568. E-mail: jackdrawin@yahoo.com.br.

*** Docente do Departamento de Psicologia da Universidade Federal de Minas Gerais (UFMG). Endereço: Avenida Antônio Carlos, 6627, sala F4030 - Pampulha, Belo Horizonte-MG, Brasil. CEP: 31270-901. Telefone: (31)3409-5027. E-mail: andreamcguerra@gmail.com.

**** Docente do Departamento de Psicologia da Universidade Federal de São João del-Rei (UFSJ). Endereço: Praça Dom Helvécio, 74, São João del-Rei-MG, Brasil. CEP 36301-160. Telefone: (32) 3379-2457. E-mail: fuadneto@ufsj.edu.br.
} 
as much as science, presents itself in a dubious manner: on the one hand, it is an inheritor of modern science; and, on the other hand, it proposes a subversion of the subject through the logic of the unconscious. The object of psychoanalytical investigation is the subject who speaks. Therefore, it is necessary to seek precision in the language realm and organize phenomena based on the hypothesis that the unconscious is structured as the language. The perspectives to think the psychoanalytical research owe fidelity to signifiers, being possibly surprised by their captures and escapes. We conclude that the emphasis on singular apprehension of reality, which is made present in social facts, is the base for the methodological orientation of psychoanalysis applied to social phenomena.

Keywords: Research. Psychoanalysis. Society. Subject. Language.

\section{RESUMEN}

Este artículo parte de una reflexión sobre la relación del psicoanálisis con la ciencia, para pensar las posibilidades de intervención del primero en investigaciones que ultrapasan la clínica. Se constata que el psicoanálisis, como la ciencia, se presenta de doble forma: por un lado es heredero de la ciencia moderna y por otro propone la subversión del sujeto por la lógica del inconsciente. El objeto de la investigación psicoanalítica es el sujeto que habla. Así, se debe buscar la precisión en el terreno del lenguaje y ordenar los fenómenos partiendo de la hipótesis de que el inconsciente está estructurado como lenguaje. Las perspectivas para pensar la investigación psicoanalítica son tributarias de la fidelidad a los significantes, dejándose sorprender por su captura y por sus escapes. Concluimos destacando que el énfasis en la aprensión singular de lo real, presentificada en el hecho social, es el pilar de la orientación metodológica del psicoanálisis aplicado a la investigación de fenómenos sociales.

Palabras-clave: Investigación. Psicoanálisis. Sociedad. Sujeto. Lenguaje.

\section{INTRODUÇÃO}

pesquisa em psicanálise no âmbito acadêmico já se encontra solidificada,
mas, para que se mantenha a especificidade da proposta psicanalítica, faz-
se necessário sempre indagar as condiçôes de possibilidades desse modo de operar. Interessa-nos, especificamente, pensar algumas diretrizes da investigação em psicanálise de fenômenos sociais.

Podemos afirmar que, por definição, a psicanálise se elucida como proposta investigativa, seja na clínica, seja no social. Dunker (2013) assinala que as características da psicanálise aplicada e do discurso analisante que a ela se liga fazem desse campo um método de invenção e descobertas. $\mathrm{O}$ autor se refere 
às seguintes características: a recordação, que é concernente ao discurso e se orienta pela história e contingências implicadas nas lembranças; a implicação, que consiste em um discurso que permite que se interrogue eticamente sobre as formaçôes de estranhamento com as quais se depara; e a transferência, que diz respeito a um discurso que se articula a uma suposição de saber, que aponta para o propósito de diálogo.

Para Dunker (2013), a colocação do pesquisador na posição de analisante pode ajudar a compreender a dubiedade presente na própria definição que Freud fez da psicanálise em Dois artigos de enciclopédia: psicanálise e teoria da libido (1923), em que a psicanálise é definida como teoria, método clínico e disciplina científica. A prática investigativa se insere, portanto, no centro da psicanálise, ainda que se expanda para além do atendimento no setting analítico.

Algumas reflexões sobre o tema da pesquisa em psicanálise, como as de Elia (1999), propõem a inserção da transferência como condição estrutural na pesquisa em psicanálise. Lo Bianco (2003), por seu turno, ao abordar as bases dos procedimentos investigativos em psicanálise, considera que, na pesquisa na área, é imperativo o reconhecimento da especificidade de seu objeto, pois tal objeto só se deixa circunscrever em análise, na qual analista e analisante estão implicados nas próprias produções inconscientes sob investigação. Pinto (2009), por sua vez, assevera que há uma dissimetria entre a política da psicanálise, que visa às singularidades das soluções encontradas pelo sujeito, ao lidar com os impasses do gozo, e a mestria dos outros laços sociais que se sustentam na forclusão do sujeito. Temos, ainda, a posição de Iribarry (2003) que, ao apresentar as condiçôes preliminares do método da pesquisa psicanalítica, propõe o exame do ponto de vista de sua singularidade e de sua relação com o significante tomado em oposição ao signo.

Este artigo segue a esteira dos supracitados e visa a alcançar os pressupostos para pensarmos a pesquisa psicanalítica de fenômenos sociais. Partiremos de uma pequena reflexão sobre a relação da psicanálise com a ciência, para, em seguida, articular as possibilidades de intervenção da psicanálise nas pesquisas que ultrapassam a cena clínica estrito senso.

\section{PSICANÁLISE E CIÊNCIA: O INCONSCIENTE}

$\mathrm{Na}$ introdução do livro A psicanálise e a investigação na universidade, os autores Ramirez e Gallo (2012) orientam que, em uma investigação psicanalítica, o pesquisador conserve a pergunta sobre qual seria a implicação do sujeito do inconsciente na investigação, uma vez que este se distingue do sujeito da investigação qualitativa e do sujeito do conhecimento ao qual se acede por meio 
da experiência sensível. Os autores afirmam que "investigar psicanaliticamente é algo que sempre propicia incertezas, que nunca se consegue dominar completamente, mas com o que é possível dar conta de um percurso, com suas conquistas, dificuldades e pontos de escansão" (Ramirez \& Gallo, 2012, p. 11).

Em que pesem os desafios inerentes à pesquisa psicanalítica, acreditamos que se torna difícil a compreensão dos diversos fenômenos sociais, se partirmos da premissa de que apenas a racionalidade e a consciência são as bases que fundamentam as ações que os indivíduos produzem, seja isolada ou coletivamente. Partilhamos da posição de Pacheco Filho (1997), que argumenta que uma visão do humano que inclua tanto a sua possibilidade de uma conformação passiva, exposta a influências, quanto em sua perspectiva dinâmica e transformadora frente ao social requer não apenas o estudo do fenômeno macrossocial, mas também o da subjetividade em suas múltiplas interações com a sociedade e a cultura.

Nesse sentido, a psicanálise distancia-se do ideal positivista que crê ser possível, com avanços futuros, aceder à verdade dos fatos. A experiência com o inconsciente, ao contrário, ensina-nos que todo acesso à verdade se dá pela via do saber. Ela, entretanto, comporta uma dimensão real que não se deixa capturar. Daí Lacan não reconhecer a psicanálise como sendo do domínio das ciências ditas do homem, dado que, se as Ciências Humanas intentam suturar o sujeito, esse projeto se mostrou, com a lógica moderna, impossível. Para justificar essa posição, Lacan $(1966 / 1998)^{1}$ recupera os teoremas de Kurt Gödel, que, provados em 1931 no âmbito da lógica matemática, radicam em duas proposições que questionam o programa de se encontrar um conjunto completo e consistente para toda a Matemática.

O primeiro teorema da incompletude afirma que nenhum sistema consistente de axiomas, cujos teoremas podem ser listados por um procedimento efetivo (por exemplo, um programa de computador que poderia ser qualquer tipo de algoritmo), seria capaz de provar todas as verdades sobre as relações dos números naturais no campo da Aritmética. Para qualquer um desses sistemas, sempre haverá afirmações sobre os números naturais que são verdadeiros, mas que não podem ser provadas dentro do sistema. O segundo teorema da incompletude, extensão do primeiro, mostra que tal sistema não pode demonstrar sua própria consistência.

Assim, o paradigma contemporâneo da ciência moderna demonstra que o intento racional e positivista, radicado no anseio de uma ciência final completa que englobaria todas as explicações dos fenômenos observáveis (em nosso caso,

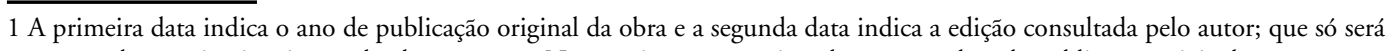
pontuada na primeira citação da obra no texto. Nas seguintes será registrada apenas a data de publicação original. 
o sujeito e os fenômenos sociais), revela-se impossível. No interior do próprio sistema, há um elemento fora do jogo. "O sujeito está, se me permitem dizê-lo, em uma exclusão interna a seu objeto" (Lacan, 1966, p. 875). Ora, é justamente daí que se extrai a materialidade do sujeito para a Psicanálise. Não pode haver a ciência do homem simplesmente porque o homem da ciência não existe; apenas seu sujeito, instituído pela Linguística, que, por ter que integrar a diferença entre enunciado e enunciação, permitiu a instalação ou a incidência do sujeito exatamente aí.

Nesse ponto, a psicanálise subverteu a própria ciência, desde seu interior. Se o fundamento da ciência moderna no século XVII, com Descartes, assentavase na delimitação e exclusão radical do sujeito por seu ato fundador, a fim de garantir, por seu método, o pensamento claro e distinto; ao mesmo tempo, esse ato se tornou condição de possibilidade do advento da subjetividade e, por consequência, do surgimento da psicanálise. Ao excluir o sujeito, sua doxa e suas paixões como estratégia para aceder à verdade, o método cartesiano instala, ele próprio, o campo subjetivo. "Cogito ergo sum”, ou seja, "penso, logo sou”. Trata-se de uma operação de exclusão, cujo ato institui um campo excluído (Elia, 2000). Ao nomear e circunscrever aquilo de que não se deve ocupar a ciência, desenhando seu Cogito, correlativamente Descartes instituiu, por exclusão, o sujeito do qual vai se ocupar a psicanálise: o sujeito fora do campo da racionalidade, exclusão interna a seu objeto. Daí o valor político da subversão psicanalítica.

Assim, do ponto de vista da psicanálise, a concepção de sujeito aponta para um ser dividido em um eu autorrepresentado como consciente, racional e supostamente senhor das suas resoluções, e um inconsciente passional, desconhecido e irracional, constantemente ameaçando de dissolução a improvável coerência e unidade do $e$.

Ramirez e Gallo (2012, p. 15), apoiados em Miller (2010), lembram que toda investigação psicanalítica comporta uma referência ao sujeito do inconsciente, e este se constitui sempre como exceção à regra. Por mais que aquela chegue a compartilhar com outros tipos de investigação perguntas semelhantes em sua formulação, sempre haverá, em seu proceder, como sucede com o sintoma, uma invenção do sujeito para responder ao que lhe causa mal-estar, marcando a singularidade que o torna único. Seu mal-estar encontra um de seus pilares na entrada do lugar simbólico a ele previamente "reservado" por meio de seus relacionamentos significativos, por intermédio das vicissitudes inerentes ao Édipo e a castração, que o arrebatam na direção de uma relação com o mundo e com os outros mediatizada pela ordenação dos símbolos da cultura. 
Assim, a relação da psicanálise com a ciência se apresenta de dupla forma: por um lado, a psicanálise é herdeira da ciência moderna e, por outro, propõe a subversão do sujeito à lógica do inconsciente. Tendo isso em mente, podemos nos perguntar sobre como operar com essa premissa do sujeito do inconsciente na investigação clínica do psiquismo quando tomamos como questão os fenômenos sociais.

\section{SOBRE O ESTADO DA ARTE OU A REVISÃO TEÓRICA A PARTIR DA PSICANÁLISE}

Freud (1930/1996), em $O$ mal-estar na civilização, destaca o contraste entre a neurose individual e seu meio considerado normal. Posteriormente, o autor faz indagações sobre como seria a aplicação dos conhecimentos psicanalíticos sem o referido contraste, no caso de uma doença coletiva. Diz ele:

E, quanto à aplicação terapêutica de nosso conhecimento, qual seria a utilidade da mais correta análise das neuroses sociais, se não se possui autoridade para impor essa terapia ao grupo? No entanto, e a despeito de todas essas dificuldades, podemos esperar que, um dia, alguém se aventure a se empenhar na elaboração de uma patologia das comunidades culturais (Freud, 1930, pp. 146-147).

Com base nessas considerações freudianas, Souza (1991) elabora duas afirmaçōes:

a) uma análise do social fica inócua se não vier acompanhada de alguma perspectiva de mudança; e

b) tal mudança é tributária de uma figura de autoridade que seja agente de um polo transferencial. Assim, considerando o convite freudiano, propõe-se, neste texto, uma reflexão acerca de como, metodológica e psicanaliticamente, podemos interrogar o fenômeno social.

No que tange à investigação em psicanálise, Gallo (2012a, p. 77), em seu texto Del método y la investigación psicoanalítica, elucida que, no campo da investigação, "método" significa "caminho a percorrer para atingir um fim". Para ele, em rigor, método não remete a um modo de fazer, mas a um particular modo de proceder, irrepetível e impossível de avaliar senão a partir do próprio sujeito. Assim entendido, o método se torna mais favorável à produção de algo novo, mesmo que seja pequeno. E, para manter a coerência com os princípios da psicanálise, é necessário estimular o "desejo pelo novo, enquanto sabemos do gozo da repetição, que significa: encontrar o mesmo, uma vez mais", como afirma Miller (2010, p. 120). 
Com relação à busca do novo versus repetição, Gallo (2012a, p. 78) enfatiza que, tanto na investigação com a psicanálise quanto na clínica psicanalítica, é indicado que se deve partir do sujeito, que assume a posição de não saber, abrindo caminho para a investigação psicanalítica. Com base em Miller (2010), em Conferências portenhas, o autor afirma que "Não podemos sustentar nenhum ensinamento somente com a repetição. Há que se ter em conta outra vertente, que é a investigação [...] que significa busca, espera do novo" (Gallo, 2012a, p. 78). Para Gallo, em uma investigação cujas teoria e metodologia se orientam pela psicanálise, é importante manter uma dialética "entre a vertente do acumulado estado da questão - e a do novo - desenvolvimento do trabalho" (Gallo, 2012a, pp. 79-80).

Segundo esse autor, o estado da questão permite evidenciar o problema a ser investigado, já que este surge a partir do que já se investigou. Além disso, o estado da arte é uma via régia para se ter acesso ao conhecimento já acumulado. Trata-se de um trabalho documental que permite reconhecer sistematicamente o conhecimento acumulado sobre o tema central da investigação e possibilita, ainda, uma avaliação do conhecimento acumulado, para estabelecer uma projeção sobre como o trabalho será desenvolvido. Essa concepção vai ao encontro das pesquisas sobre o tema, desenvolvidas por Galeano (2007).

Ademais, se entendermos que o acúmulo não indica depósito, retenção ou adição, mas antes avanço operado a partir do ponto em que o saber se cruza sobre o real, mesmo a revisão teórica, ou o estado da arte, ganha outra dimensão. Ela é retomada por meio dos pontos de ancoragem, de capitonagem, que circunscrevem o objeto, sem capturá-lo. Ao reler os textos matriciais (ou primários, como os chamamos), e mesmo ao revisar a atualidade do tema sob investigação (fonte secundária), buscamos cernir os principais aspectos já discutidos e, sobretudo, indicar as zonas descobertas a explorar.

Gallo afirma que, na investigação com a psicanálise, a "ignorância seria o suporte de um querer saber, da disposição a entregar-se a uma indagação que reforme a maneira de pensar, que implique um esforço de formalização e de reformulação permanente do já sabido" (Gallo, 2012a, p. 81). Nota-se que, nesse tipo de investigação, a ênfase está nas perguntas e não na repetição ou na oferta de respostas, ou seja, o saber está por formar-se. Além disso, o investigador pode duvidar ou desconsiderar ideias preconcebidas, supondo um saber ao outro.

Assim como o sintoma porta uma resposta para a qual o analista busca, junto ao analisante, a formulação da(s) pergunta(s) a que ele serve, também o psicanalista como pesquisador retoma os elementos da realidade junto aos sujeitos, tomando-os na qualidade de respostas cujas perguntas ainda não foram 
estabelecidas. A formulação das perguntas (hipóteses) e sua circunscrição (objeto) orientam o roteiro ou recorte para pesquisa, indicando o que deve ser lido e o que deve ser descartado.

O objeto que está em jogo na investigação psicanalítica é o sujeito que fala. Por isso, deve-se buscar a precisão no terreno da linguagem e ordenar o campo dos fenômenos a partir da hipótese de que o inconsciente está estruturado como linguagem. $\mathrm{Na}$ investigação psicanalítica, o discurso tem valor de dado, e a noção de realidade com a qual se trabalha inclui a realidade psíquica. Assim, o que mais importa não são os fatos em si, mas o que o sujeito, as instituições ou as teorias conseguem nomear desses fatos, sejam reais ou fantasiados, assim como a formalização rigorosa da pergunta (Gallo, 2012a, pp. 87; 91).

No texto Método, surpresa, subjetividade, verdade e saber, Gallo (2012b) esclarece ainda que a investigação com a psicanálise importa por "estabelecer índices da subjetividade - índices do inconsciente, que não são equivalentes ao oculto e latente, mas ao lugar de onde, em rigor, se tenta ler o que faz marca significante" (Gallo, 2012b, p. 114). Esse autor, apoiado em Miller (2005, p. 39), afirma que o essencial, do ponto de vista metodológico, não é revelar o não dito ou o que escapa à consciência, mas "localizar o dizer do sujeito, ou seja, [...] a enunciação, que significa a posição que aquele que enuncia toma com relação ao enunciado" (Gallo, 2012b, p. 114).

No sentido proposto por esse autor, a prioridade "não está no geral e repetível, no estudo do típico, mas no excepcional, dos detalhes marginais e irrelevantes, o avaliado como irrepetível e menos ligado ao típico" (Gallo, 2012a, p. 94). Nessa via, para o método psicanalítico, os indícios mais reveladores são aqueles que habitualmente são deixados em plano secundário por apontar uma falha no saber já sabido, uma vez que esse saber ainda não foi definido nem descrito. Porém, para o método orientado pela psicanálise, esse saber se constitui em abertura para o possível surgimento de uma verdade que, até esse momento, esse mesmo saber vinha obturando.

Agamben (2010), numa análise filosófica da política contemporânea, auxilianos a tornar mais precisa a dimensão real a que estamos nos referindo. Ao trabalhar o exemplo e a exceção, ele evoca o real como ponto inapreensível de um sistema, o que nos permite tomar a exceção como ponto de orientação na pesquisa psicanalítica, não o exemplo. $\mathrm{O}$ exemplo precisa ser excluído para fundar a possibilidade da inclusão, de um conjunto de iguais. E a exceção, mais do que o caso normal, apenas confirma a regra, pois a regra mesma vive da exceção. Se a exceção é capturada fora, não sendo simplesmente excluída (Agamben, 2010, p. 29), ela se situa em posição simétrica e oposta ao exemplo. Assim, a 
exceção é uma exclusão inclusiva, enquanto o exemplo funciona antes como uma inclusão exclusiva. Enquanto o exemplo demonstra seu pertencimento a uma classe, "diverso é o mecanismo da exceção. Enquanto o exemplo é excluído do conjunto na medida em que pertence a ele, a exceção é incluída no caso normal justamente porque não faz parte dele" (Siqueira, 2016, p. 35).

Eis, portanto, a dimensão real que organiza a revisão teórica ou orienta a direção para se aceder ao estado da arte em uma investigação em psicanálise: situar o ponto de escape ao corpo teórico, orientado pelo real. E de onde parte o psicanalista ou, em outros termos, qual deve ser sua posição como pesquisador?

\section{FORMAS DE APLICAÇÃO DA PESQUISA PSICANALÍTICA A FENOOMENOS SOCIAIS}

Gallo (2012a, pp. 96-97) lembra que, na pesquisa orientada pela psicanálise aplicada a problemas sociais, os princípios da teoria psicanalítica permanecem sendo seus conceitos fundamentais (inconsciente, pulsão, transferência e repetição). Assim, é imprescindível que o investigador assimile e aplique esses princípios de modo rigoroso e preciso, levando em conta a pergunta que o orienta para garantir que o constructo continue sendo psicanálise. Dedicamonos agora a cernir em que consiste a aplicação da psicanálise à investigação de fenômenos sociais.

Apesar de a pesquisa psicanalítica aplicada a fenômenos sociais integrar a obra de Freud desde suas primeiras investigações, no Brasil e em alguns países da Europa e da América Latina, ela tem se tornado cada vez mais visível, a partir dos primeiros anos da década de 2000 , devido ao crescente número de pesquisas e publicações, assim como à ampliação do campo de atuação para psicanalistas, psicólogos, psiquiatras, trabalhadores sociais, trabalhadores da saúde mental e outros que estão implicados com a clínica e com o real do mal-estar de nossa civilização. Esses profissionais, em sua prática, realizam psicanálise aplicada à luz da psicanálise pura, independentemente de seu locus de atuação ser o consultório, uma instituição, ou outro espaço. Daí a pesquisa psicanalítica de fenômenos sociais ser hoje uma realidade a ser pensada e enfrentada com maior rigor.

Ramirez (2007, pp. 11-12), no texto El psicoanálisis aplicado a lo social, esclarece que sua abordagem não aponta para a sociologia do fenômeno, e sim, em um primeiro plano, para a subjetividade implicada neste. Para esse autor, o método da psicanálise aplicada consiste na confrontação dos indícios dessa subjetividade extraídos de testemunhas de atores sociais, envolvidos com uma hipótese explicativa da psicanálise denominada "análise dos indícios", com base na qual inferimos a emergência da particularidade do caso ou do fenômeno analisado. A eficácia desse método incide sobre a análise e a interpretação dos enunciados nos testemunhos. 
A psicanálise aplicada ao social funciona do mesmo modo, quando se aplicam seus princípios, à análise de interpretação de enunciados tomados de um texto ou sobre testemunhos gravados pelo psicanalista. Em ambos os casos, trabalha-se com a materialidade significante e o real que a ela escapa sob a forma de gozo.

Vale assinalar que a leitura atenta das obras de Freud permite compreender que os procedimentos por ele realizados consistiam na transcrição das sessões logo após seu término. Em sucessivas leituras do material anotado, Freud começava a pensar, fazendo sublinhados, anotações ou acréscimos às margens dos parágrafos, tal como um filólogo ao acrescentar apontamentos a um documento antigo. A reelaboração desse material, que inclui as notas de pé de página e os pontos de vista críticos de suas próprias observações prévias, deu lugar ao que hoje se conhece como psicanálise. É nesse sentido que se diz que a psicanálise é uma prática da letra, pura ou aplicada; "Significa que se trata de ler o relato do paciente com o valor de transferência textual indicada" (Ramirez, 2012a, p. 130).

Ramirez (2012a, p. 131) elucida que a aplicação da psicanálise aos fenômenos sociais, na prática, parte dos princípios psicanalíticos, mas também de seu método, e explica que Freud distingue dois momentos do trabalho analítico,

Um de escuta do analisante, para a qual se teorizou uma técnica e uma ética - a instalação da transferência, o uso da interpretação, a atenção flutuante e a suspensão dos prejuízos do analista -; e outro momento de escrita e elaboração, no qual já não se trata de escutar, mas de ler e pensar, para finalmente produzir o material que se pode publicar (Ramirez, 2012a, p. 131).

Dessa forma, entende-se que, desde os primórdios de suas investigações, Freud levou em conta a psicanálise aplicada, a qual preserva os princípios e o método da psicanálise e, mesmo utilizada em novo contexto, continua sendo fiel aos seus pressupostos e princípios.

Além da materialidade significante recolhida nas investigaçôes, Ramirez (2007) salienta que, desde seu começo, a psicanálise aplicada ao social despertou uma preocupação sem fundamento, por se tratar de uma prática distinta do exercício da clínica individual. O autor, todavia, demonstra que Freud apresentou à Sociedade Psicanalítica de Viena a coleção de textos de psicanálise aplicada, na sessão de 17 de outubro de 1906. As obras dessa coleção se tornaram exemplos da aplicação dos conhecimentos psicanalíticos a questões de arte, literatura, história das civilizaçôes e das religiôes. Posteriormente, Freud criou a revista Imago, na qual publicou as primeiras versões de Totem e tabu, em 1913, marcando uma primeira orientação para a psicanálise aplicada ao social. 
Nessa mesma direção, Ramirez (2007) demonstra que a eficácia da psicanálise aplicada ao âmbito coletivo pôde ser observada desde o atendimento aos enfermos de neurose de guerra na Primeira Guerra Mundial, nos trabalhos de George Simmel e Max Eitigong no Instituto de Berlim, onde muitas pessoas foram atendidas. Destaca, ainda, os trabalhos das psicanalistas Anna Freud e de Dorothy Burlingham, na Segunda Guerra Mundial, atendendo crianças nos refúgios durante os bombardeios de Londres, e também o trabalho de Bruno Bettelheim com os sobreviventes do holocausto.

$\mathrm{O}$ autor ainda assinala que a psicanálise, aplicada à terapêutica e no marco das urgências sociais, também se fez presente por meio dos psicanalistas nos serviços de emergências para tratar os traumatizados pelos atentados de 11 de setembro de 2001, em Nova Iorque, e em 11 de março de 2004, em Madri. Está presente também nos Centros de Atenção de Urgências Subjetivas em grandes cidades, influenciadas pela Associação Mundial de Psicanálise, onde se recebem muitas pessoas que, em outras circunstâncias, não poderiam ser atendidas por um psicanalista.

Ramirez (2007) salienta, ainda, que o breve histórico relatado (que deixa de lado a intensa presença da psicanálise nos serviços de saúde e assistência social na América do Sul) serve para mostrar que a psicanálise aplicada ao social "não é uma psicanálise de segunda classe, diferente de uma psicanálise pura, praticada na clínica individual e pautada em regras standards" (Ramirez, 2007, p. 19). Na verdade, a psicanálise é aplicada quando recai na terapêutica e, mesmo quando seus princípios são utilizados em um novo âmbito, continua sendo psicanálise ao afirmar seus fundamentos.

É interessante notar que Freud, em Psicologia das massas e a análise do eu, apresenta a seguinte afirmativa:

O contraste entre a psicologia individual e a psicologia social ou de grupo, que à primeira vista pode parecer pleno de significação, perde grande parte de sua nitidez quando examinado mais de perto. [...] apenas raramente e sob certas condiçõos excepcionais, a psicologia individual se acha em posição de desprezar as relações desse indivíduo com os outros (Freud, 1921/1996, p. 91).

Concordamos com a afirmação de Calligaris (1991) (resguardando as materialidades diferentes de apresentação significante desses termos) de que não existe psicanálise do individual e outra "aplicada" ao sintoma social. A singularidade é sempre efeito de uma rede discursiva, que se faz presente no campo societário e discursivo.

Dessa forma, podemos perceber que o outro é necessário, visto que auxilia na montagem do fantasma, à sua agitação, e o pouco de gozo que se recupera 
em seu nível requer a vida em grupo. Por essa razão é que um gozo está em jogo no socius e vem a se desenvolver na base do estatuto ontológico que o grupo estipula para cada um. É precisamente na rejeição dessas cisões artificiais, entre indivíduo e sociedade completamente autônomos, ou entre um corpo e uma mente nitidamente apartados, que a psicanálise põe à mostra as dificuldades do projeto de uma ciência dos fatos humanos que destrói pela hipermolecularização o seu objeto (Pacheco Filho, 1997).

Observando o fato de que Freud incluiu a psicanálise aplicada desde o início de suas investigaçóes, Ramirez (2012a, p. 130) nota que as teorias freudianas provêm desse lugar onde os enunciados do paciente se põem a trabalhar. Nesse espaço, a aparente passividade do psicanalista se põe em ação, por meio da formalização dos casos. E a psicanálise pura em dobradiça com a psicanálise aplicada reforçam, ambas, a fidelidade teórico-clínica aos princípios psicanalíticos.

Na perspectiva desse autor, na investigação com a psicanálise aplicada ao social, supõe-se que a causa está escondida, é desconhecida, mas pode surgir dos ditos dos entrevistados, dos discursos sobre o fenômeno, chamados de "'categorias emergentes' $[. .$.$] as quais aparecem discretas, como noçôes, ocorrências, ideias$ loucas sobre o assunto, e que logo se repetem em outros entrevistados até que satura o material" (Ramirez, 2012b, p. 145). O autor esclarece que se denominam emergentes porque as ideias que se buscam não são consideradas nas categorias a priori, nem nos conceitos do marco teórico da investigação, mas surgem e se repetem nos ditos dos entrevistados. Nesse sentido, Miller (2006) afirma que:

O sujeito-suposto-saber [na análise] é somente a outra face do não saber do sujeito em análise. O sujeito-suposto-saber surge da palavra mesma. Que expressa esse não saber do sujeito senão o que Freud chamou de repressão? Freud chamou repressão a um não saber do sujeito localizado em pontos decisivos, determinantes, de suas vivências. O que é apresentado como a noção da causa escondida é a noção mesma de repressão (Miller, 2006, p. 94).

Em consonância com o exposto, compreende-se que o sujeito suposto saber surge do discurso do sujeito, que dá lugar ao um saber recalcado, ou seja, o sujeito diz não saber, todavia "ele sabe, sem saber que sabe. Por isso, o inconsciente se trata de um saber reprimido, exatamente um saber que se apresenta como não saber" (Miller, 2006, p. 192). Na investigação psicanalítica, portanto, "partese da suposição de que há um saber no real do fenômeno que estudamos, e este saber pode se revelar no instante em que se está disposto a encontrá-lo” (Ramirez, 2012b, p. 147).

Daí na investigação de fenômenos sociais com a psicanálise, as entrevistas investigativas assumirem lugar privilegiado (Ramirez, 2012b), como acontece 
com a associação livre nas pesquisas de matiz clínico. $\mathrm{Na}$ análise clínica das entrevistas, busca-se o sintoma e os significantes que o sujeito usa para descrever seu sofrimento. No que hoje se denomina investigação qualitativa, as "categorias emergentes" equivalem aos sublinhados, anotações ou acréscimos que Freud fazia nos manuscritos, após sucessivas leituras dos mesmos, para chamar a atenção do leitor. Desse modo, compreende-se que a elaboração do material é formalizada a partir da análise da escrita dos ditos dos entrevistados.

Podemos, portanto, depreender de Freud três perspectivas para pensar a pesquisa psicanalítica de fenômenos sociais: a clínica, a teórica e a aplicada. Cada qual exige um procedimento próprio de investigação, orientado pela fidelidade aos significantes, mas que se deixa surpreender por sua captura e por seus escapes, ora privilegiando a escuta clínica, ora o texto teórico, ora a entrevista. Trata-se de materialidades diferentes de apresentação significante com modulações que interferem no modo de proceder e abordar o objeto de investigação, sendo-lhe, entretanto, sempre afim.

\section{CONSIDERAÇÕES FINAIS}

Consideramos que um importante aporte da psicanálise para o conhecimento dos fenômenos sociais é a forma com que ela articula a construção da subjetividade e do laço social, descortinando os modos pelos quais as transformações em um desses polos refletem-se em mudanças inevitáveis no outro. A literalidade do fato é interpretada com base nos significantes que enlaçam o sujeito e sua posição de gozo no fato social. Nesse sentido, a dimensão macrossocial é lida pelo filtro subjetivo que a interpreta, evidenciando outro prisma de análise no qual se revela a posição a partir da qual o sujeito toma partido, participa da determinação macropolítica que o envolve no fenômeno social observado.

Para que tal contribuição seja efetiva, é fundamental que a ênfase na maneira singular de apreensão e escape, presentificada no texto interpretado, seja a base da orientação metodológica da psicanálise. Nas diversas formas materiais de apresentação dos significantes presentes nas perspectivas para pensar a pesquisa psicanalítica de fenômenos sociais, é possível mostrar que a precariedade do simbólico é condição essencial para o desejo, para o aparecimento do real e da verdade do sujeito e também para a pesquisa (Pinto, 2009).

Essa postura ética não desconsidera as determinações macroestruturais e circunstanciais do fenômeno social, apenas prima por lê-las da perspectiva que determina o campo que circunscreve as possibilidades de respostas e interpretações do sujeito. Dessa forma, a psicanálise traz sua contribuição à leitura complexa dos fatos sociais ao lado de outros saberes, compreendendo 
esses fatos como pedaços de real alcançados não completamente pela linguagem e pela racionalidade, mas dispostos nos significantes, fantasias e semblantes que moldam o acesso à realidade.

A pesquisa em psicanálise é, assim, uma atividade que permite que seu objeto seja enunciado e escrito no texto do Outro. A consequência desse fato, conforme apontado no transcorrer deste artigo, é que a psicanálise não pode adulterar-se com o intuito de atender às reivindicações dos ideais científicos sob pena de perder sua vertente metodológica e impossibilitar a subjetivação de seu método e de sua teoria, renunciando, dessa forma, a atualizar a castração experienciada analiticamente na linguagem. Ao contrário, parte desse limite exatamente como horizonte possível da pesquisa psicanalítica dos fenômenos sociais. 


\section{REFERÊNCIAS}

Agamben, G. (2010). Homo sacer: o poder soberano e a vida nua. Belo Horizonte: UFMG.

Calligaris, C. (1991). Liminar. In L. T. Aragão, C. Calligaris, J. F. Costa, \& O. Souza, Clínica do social. (pp. 105-118). São Paulo: Escuta.

Dunker, C. I. L. (2013). A psicose na criança: tempo, linguagem e sujeito. São Paulo: Zagodoni.

Elia, L. (1999). A transferência na pesquisa em psicanálise: lugar ou excesso? Psicologia, Reflexão e Crítica, 12(3).

Elia, L. (2000). Psicanálise: clínica e pesquisa. In S. Alberti \& L. Elia, Clínica e pesquisa em psicanálise. (pp. 19-35). Rio de Janeiro: Rios Ambiciosos.

Freud, S. (1921/1996). A psicologia das massas e a análise do eu. In J. Salomão (Trad.), Edição standard brasileira das obras psicológicas completas de Sigmund Freud (Vol. 7, pp. 113-130). Rio de Janeiro: Imago, 1996. (Publicado originalmente em 1921).

Freud, S. (1930/1996). O mal-estar na civilização. In J. Salomão (Trad.), Edição standard brasileira das obras psicológicas completas de Sigmund Freud (Vol. 21, pp. 67-110). Rio de Janeiro: Imago, 1996. (Publicado originalmente em 1929).

Galeano, M. E. (2007). Estrategias de investigación social qualitativa: el giro en la mirada. Medellín: La Carreta.

Gallo, H. (2012a). Del método y la investigación psicoanalítica. In M. E. Ramirez \& H. Gallo. El psicoanálisis y la invetigación en la universidad. (pp. 77-103). Buenos Aires: Grama.

Gallo, H. (2012b). Método, sorpresa, subjetividad, verdad y saber. In M. E. Ramirez \& H. Gallo. El psicoanálisis y la invetigación en la universidad. (pp. 105-127). Buenos Aires: Grama.

Iribarry, I. N. (2003). O que é pesquisa psicanalítica? Ágora, 6(1), 115-138.

Lacan, J. (1966). A ciência e a verdade. In J. Lacan, Escritos. (pp. 869-892). Rio de Janeiro: Jorge Zahar, 1998. (Publicado originalmente em 1966).

Lo Bianco, A. C. (2003). Sobre as bases dos procedimentos investigativos em psicanálise. Psico-USF, 8(2), 115-123. 
Miller, J.-A. (2005). Introdución al método psicoanalítico. Buenos Aires: Paidós.

Miller, J.-A. (2006). Como se inventan nuevos conceptos en psicoanálisis? In J.A. Miller, Introducción a la clínicia lacaniana. Barcelona: ELP-RBA.

Miller, J.-A. (2010). Conferencias porteñas (Tomo 3). Buenos Aires: Paidós.

Pacheco Filho, R. (1997). O conhecimento da sociedade e da cultura: a contribuição da psicanálise. Psicologia e Sociedade: Revista da Associação Brasileira de Psicologia Social (Abrapso), 9(1/2), 124-138.

Pinto, J. M. (2009). Uma política de pesquisa para a psicanálise. Clinicaps: Impasses da Clínica, 7.

Ramirez, M. E. (2007). El psicoanálisis aplicado a lo social. In M. E. Ramirez, Órdenes de hierro: ensayos de psicoanálisis aplicado a lo social. (pp. 11-19). Medellín: La Carreta.

Ramirez, M. E. (2012a). El método clínico de Freud aplicado a la investigación de fenómenos sociales. In M. E. Ramirez \& H. Gallo. El psicoanálisis y la invetigación en la universidad, (pp. 129-141). Buenos Aires: Grama.

Ramirez, M. E. (2012b). Qué és e cómo se produce un nuevo concepto en el psicoanálisis? In M. E. Ramirez \& H. Gallo. El psicoanálisis y la invetigación en la universidad. (pp. 143-161). Buenos Aires: Grama.

Ramirez, M. E. \& Gallo, H. (Orgs.) (2012). El psicoanálisis y la invetigación en la universidad. Buenos Aires: Grama.

Siqueira, F. (2016). Segregação e violência: um estudo sobre o sistema de vida e da guerra entre adolescentes e jovens envolvidos com a criminalidade (Dissertação de Mestrado). Universidade Federal de Minas Gerais, Programa de Pós-Graduação em Psicologia, Belo Horizonte.

Souza, O. (1991). Reflexões sobre a extensão dos conceitos e da prática. In L. T. Aragão, C. Calligaris, J. F. Costa \& O. Souza, Clínica do Social. (pp. 75-92). São Paulo: Escuta. 